\title{
Steel fiber high-strength reinforced concrete: a new solution for earthquake strengthening of old $\mathrm{R} / \mathrm{C}$ structures
}

\author{
A. G. Tsonos \\ Department of Civil Engineering, Aristotle University of Thessaloniki, \\ Thessaloniki, Greece
}

\begin{abstract}
In this study a new innovative method of earthquake-resistant strengthening of reinforced concrete structures is presented for the first time. Strengthening according to this new method consists of the construction of steel fiber highstrength concrete jackets without conventional reinforcement, which is usually, applied in the construction of conventional reinforced concrete jackets (i.e. longitudinal reinforcement, stirrups, hoops). The proposed in this study new innovative steel fiber high-strength or ultra high-strength concrete jackets were proved to be much more effective than the reinforced concrete jackets and the FRP-jackets when used for the earthquake-resistant strengthening of reinforced concrete structural members.
\end{abstract}

Keywords: steel fiber high-strength concrete, reinforced concrete jackets, beamcolumn joints, columns, cyclic loads.

\section{Introduction}

Damage incurred by earthquakes over the years has indicated that many reinforced concrete $(\mathrm{R} / \mathrm{C})$ buildings, designed and constructed during the 1960s and 1970s, were found to have serious structural deficiencies today. These deficiencies are mainly due to lack of capacity design approach and/or poor detailing of the reinforcement. As a result, lateral strength and ductility of these structures were minimal and hence some of them collapsed [1-3]. One of the most popular pre-and post-earthquake retrofitting methods for columns, beamcolumn joints and walls is the use of reinforced concrete jacketing. In retrofitting 
building columns, b/c joints and walls with outer $\mathrm{R} / \mathrm{C}$ jackets, the usual practice consists of first assembling the jacket reinforcement cages, arranging the formwork and then placing the concrete jacket [4-8]. Shotcrete can be used in lieu of conventional concrete in the repair works and, in some cases, offers advantages over it, the choice being based on convenience and cost.

The wrapping of reinforced concrete members (usually columns, b/c joints and walls) with fiber-reinforced polymer (FRP) sheets including carbon (C), glass (G) or aramid (A) fibers, bonded together in a matrix made of epoxy, vinylester or polyester, has been used extensively through the world in numerous retrofit applications in reinforced concrete buildings. These are recognised as alternate strengthening systems to conventional methods such as plate bonding and shotcreting [9-11].

The best choice of the appropriate retrofitting method highly depends on the feasibility of the method, on the cost and on the simplicity of the application. Of course, it is well known that the works related to strengthening of buildings have higher difficulties and cost compared to the usual construction works related to the construction of new reinforced concrete buildings.

According to the above conception it would be very interesting to create and introduce in the marketing a new method of retrofitting old reinforced concrete structures, as effective as the other methods of retrofitting but simpler in application and more economical. An earthquake strengthening system with the aforementioned qualifications would be very competitive among the others.

Henager [12], successfully replaced all the hoops of the joint region and part of the hoops of the critical regions of the adjacent beam and column of an earthquake-resistant beam-column subassemblage, by steel fibers $(1.67 \%$ fiber volume fraction is used). This replacement involved 50\% reduction in building costs.

Fiber Reinforced Concrete or Shotcrete has been successfully applied in many construction applications eliminating or significantly reducing the conventional reinforcement of $\mathrm{R} / \mathrm{C}$ structures and reducing the construction costs.

The advantages of Fiber Reinforced Concrete has been worldwide recognised, however has not been found yet a reliable way of application of this material in the retrofitting of old reinforced concrete structures, by eliminating or significantly reducing the conventional reinforcement of the $\mathrm{R} / \mathrm{C}$ jacketings and generally by reducing the cost of retrofitting compared to that involved by the use of other strengthening methods as plate bonding and FRPs. A relatively new process called SIMCON (slurry infiltrated Mat Concrete) developed by Hackman et al. [13], seems to be very effective in strengthening applications. SIMCON is made by infiltrating continuous steel fiber-mats, with specially designed cement-based slurry. Nevertheless, SIMCON technique has the same disadvantages as FRPs. Their strengthening layers wrap usually horizontally the columns and the walls increasing their shear strength and ductility, but these layers are terminating in the slabs of the strengthening reinforced concrete buildings. The strengthening layers could not effectively pass through the slabs, thus these layers could not increase the flexural strength of the columns and walls and could not effectively retrofit the beam-column joint regions. The 
existing experimental results related to the retrofitting of beam-column subassemblages of reinforced concrete structures demonstrated significant damage concentration in the joint regions, although the subassemblages used were of planar-type, without slabs and the retrofitting works related to SIMCON application were easy [14].

\section{The proposed new innovative strengthening method}

An important experiment was conducted by Tsonos [16]. An exterior beamcolumn subassemblage $\mathrm{L}_{3}$ poorly detailed in the joint region was subjected to unidirectional reversed cyclic lateral loading. The joint region of this subassemblage was representative of the joint regions of old structures built during the 1960s and 1970s. The subassemblage was reinforced in the joint region by one hoop of diameter $8 \mathrm{~mm}$ instead of the five hoops of the same diameter required by the ACI-ASCE Committee 352 (ACI 352R-02) [16]. The joint shear stress of the specimen was higher than the maximum allowable joint shear stress by the same Committee $\left(\tau_{\text {joint }}=1.36 \sqrt{f_{\mathrm{c}}^{\prime}} \mathrm{MPa}>\tau_{\text {permitted }}=\right.$ $\left.1.0 \sqrt{\mathrm{f}_{\mathrm{c}}^{\prime}} \mathrm{MPa}\right)$. As expected, this specimen failed in pure and premature joint shear failure from the early stages of the seismic-type loading. The removal and replacement of the damaged concrete in the joint by a non-shrink, nonsegregating steel fiber concrete of high-strength with only $0.5 \%$ fiber volume fraction and the removal and replacement of the damaged concrete cover of part of the columns' critical regions with the same steel fiber high-strength concrete (fig. 1), resulted in a pure beam failure, when the repaired subassemblage $\mathrm{RL}_{3}$ was imposed to the same loading as the original control subassemblage $\mathrm{L}_{3}$.

The above experiment led us to the idea of using the same non-shrink, nonsegregating steel fiber high-strength concrete for the strengthening of old reinforced concrete buildings, by jacketing without conventional reinforcement, longitudinal bars or hoops $[17,18]$. For this purpose, it was decided to increase the fiber volume fraction from $0.5 \%$ to $1 \%$. The experimental results showed that the proposed new type of jacketing by steel fiber high-strength concrete with $1 \%$ fiber volume fraction was as effective as the other two types of retrofitting by reinforced shotcrete jacket and by FRP-jacket. A cost reduction of the order of $50 \%$ was computed in the application of the new proposed intervention scheme compared to the cost of application of reinforced shotcrete jacket. The compressive and tensile strengths of the non-shrink, non-segregating steel fiber concrete used, were $66 \mathrm{MPa}$ and $8 \mathrm{MPa}$ respectively. A patent No 1005657 was awarded to Professor Tsonos [20] by the Greek Industrial Property Organization for the above invention.

In order to increase the effectiveness of the proposed new type of retrofitting it was decided to orient the research to two distinct directions:

a. To increase the steel fiber volume fraction in the non-shrink, nonsegregating steel fiber concrete of high-strength used for the construction of the new innovative jackets, and

b. To increase the compressive strength of the high-strength fiber reinforced 
concrete from $70 \mathrm{MPa}$ to $120 \mathrm{MPa}$ (final aim is to increase the strength above $150 \mathrm{MPa})$ and to increase also the tensile strength of the steel fiber concrete.

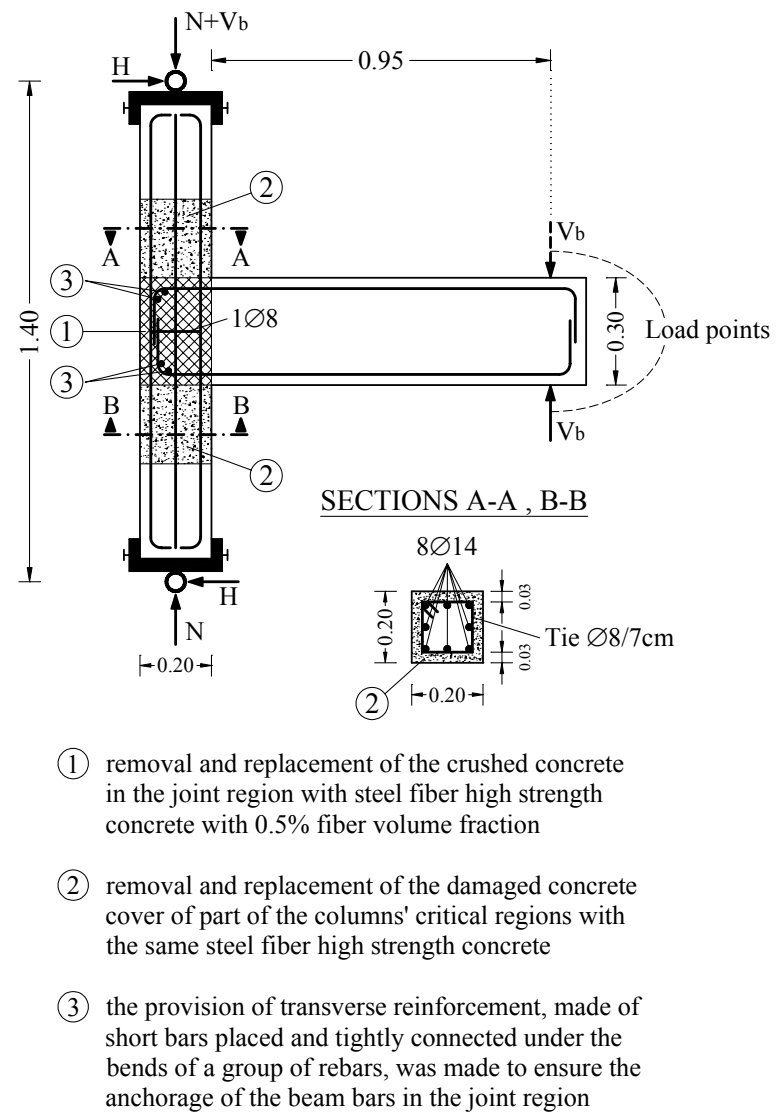

Figure 1: $\quad$ Details of repaired specimen $\mathrm{RL}_{3}$.

\section{Improvement of the effectiveness of the proposed new method}

A large experimental program was organized. Six identical exterior beamcolumn subassemblages were constructed using normal weight concrete and deformed reinforcement. The test specimens were 1:2 scale models of the representative $40 \mathrm{~cm} \times 40 \mathrm{~cm}$ square columns and beam-column joints which are usually found in building constructions within Greece and Europe in general. The columns and b/c joints of these specimens were poorly detailed in order to represent columns and b/c joints of old buildings built in 1960s and 1970s. In figure 2 are shown the dimensions and cross-sectional details of these specimens $\mathrm{O}_{3}, \mathrm{~W}_{2}, \mathrm{M}_{1}, \mathrm{M}_{2}, \mathrm{M}_{3}$, and $\mathrm{M}_{4}$. Their columns had less longitudinal and transverse reinforcement than the modern columns and their joint regions had not joint 
hoops, the joint shear stress were $2.20 \sqrt{\mathrm{f}_{\mathrm{c}}^{\prime}} \mathrm{MPa}>1.0 \sqrt{\mathrm{f}_{\mathrm{c}}^{\prime}} \mathrm{MPa}$, and the flexural strength ratios of these specimens were lower than 1.0. The concrete compressive strength of these original specimens was approximately $8.50 \mathrm{MPa}$. Thus, a premature joint shear failure is expected for all these subassemblages during a seismic type loading. All these original specimens were subjected to cyclic lateral load histories so as to provide the equivalent of severe earthquake damage. In figure 4 is shown the failure mode of the representative specimen $\mathrm{O}_{3}$ and its hysteresis loops. The failure of $\mathrm{O}_{3}$ was concentrated mainly in the joint which lost almost all of the core's concrete since the shear forces acting in the beam-column joints are significantly higher than those acting in their adjacent columns [19].

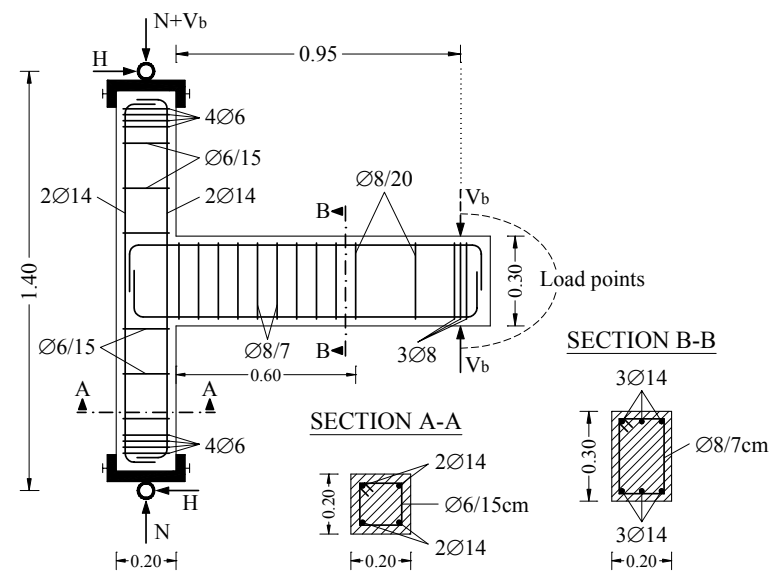

Figure 2: Dimensions and cross-sectional details of original subassemblages $\mathrm{O}_{3}, \mathrm{~W}_{2}, \mathrm{M}_{1}, \mathrm{M}_{2}, \mathrm{M}_{3}$, and $\mathrm{M}_{4}$.

In the following are described in brief the retrofitting works for specimens $\mathrm{O}_{3}$, $\mathrm{W}_{2}, \mathrm{M}_{1}, \mathrm{M}_{2}, \mathrm{M}_{3}$ and $\mathrm{M}_{4}$.

1. Specimen $\mathrm{O}_{3}$ was retrofitted by reinforced concrete jacket in the columns and beam-column joint region. The compressive strength of the jacket's concrete was $31.70 \mathrm{MPa}$. Deformed bars were used for the construction of the steel cage of the jacket. After the interventions this specimen was designated $\mathrm{SO}_{3}$. In figure 3 are shown the dimensions and cross-sectional details of the $\mathrm{SO}_{3}$.

Specimen $\mathrm{W}_{2}$ was strengthened by a high-strength fiber jacketing in the joint region and on the columns (see figure 3 ). The damaged concrete of the joint region of specimen $\mathrm{W}_{2}$ was removed and replaced by a premixed, nonshrink, rheoplastic, flowable and non-segregating concrete of high-strength. The repaired and subsequently strengthened specimen was named $\mathrm{FW}_{2}$. The design for the retrofit process with carbon fiber-reinforced polymer sheets (CFRPs) was based on $\mathrm{E}_{\mathrm{f}}=235 \mathrm{GPa}, \mathrm{t}_{\mathrm{f}}=0.11 \mathrm{~mm}\left(\mathrm{t}_{\mathrm{f}}=\right.$ layer thickness) and $\varepsilon_{\mathrm{fu}}=1.5 \%\left(\varepsilon_{\mathrm{fu}}=\right.$ ultimate FRP strain $)$. 


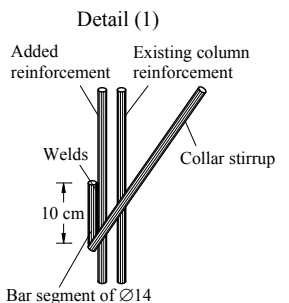

Detail (2)
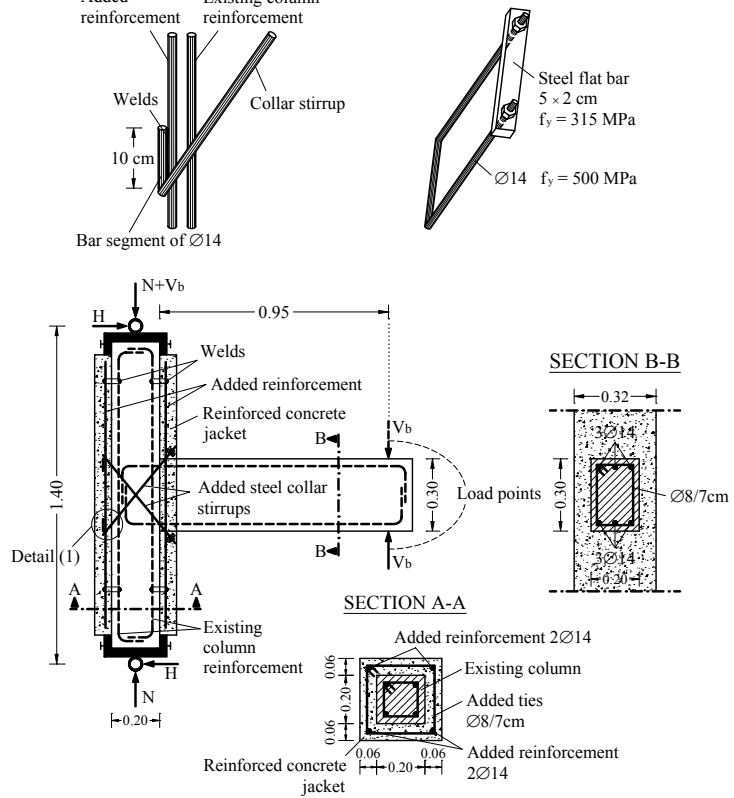

Specimen $\mathrm{SO}_{3}$

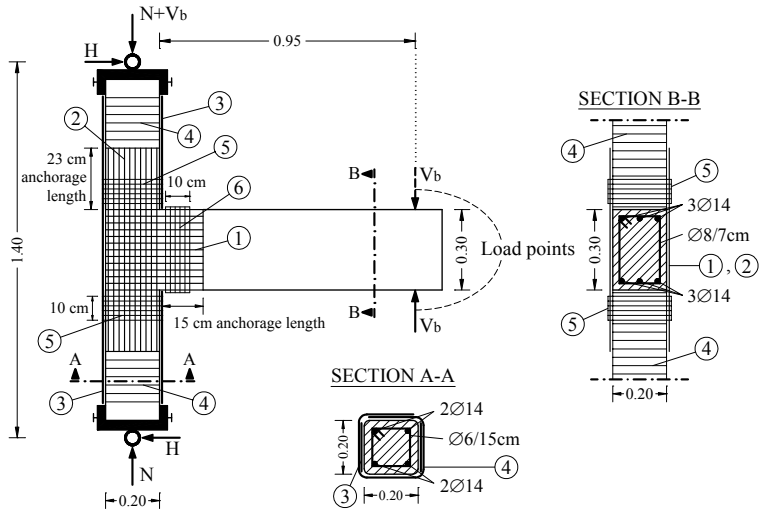

(1) 2 layers of CFRPs for increasing the horizontal shear strength of the joint

(2) 5 layers of CFRPs at the front side and 5 layers at the back side for increasing the vertical shear strength of the joint

(3) 5 layers of CFRPs for increasing the flexural strength of columns

(4) 2 layers of CFRPs for increasing the shear strength of columns

(5) 4 layers of CFRPs, $100 \mathrm{~mm}$ in width, to prevent premature debonding of column strengthening layers

(6) 4 layers of CFRPs, $100 \mathrm{~mm}$ in width, to secure the anchorage length of the joint layers

Specimen $\mathrm{FW}_{2}$

Figure 3: Jacketing of column and beam-column connection of subassemblages $\mathrm{SO}_{3}, \mathrm{FW}_{2}, \mathrm{HSFM}_{1}, \mathrm{HSFM}_{2}, \mathrm{HSFM}_{3}$ and $\mathrm{HSFM}_{4}$. 


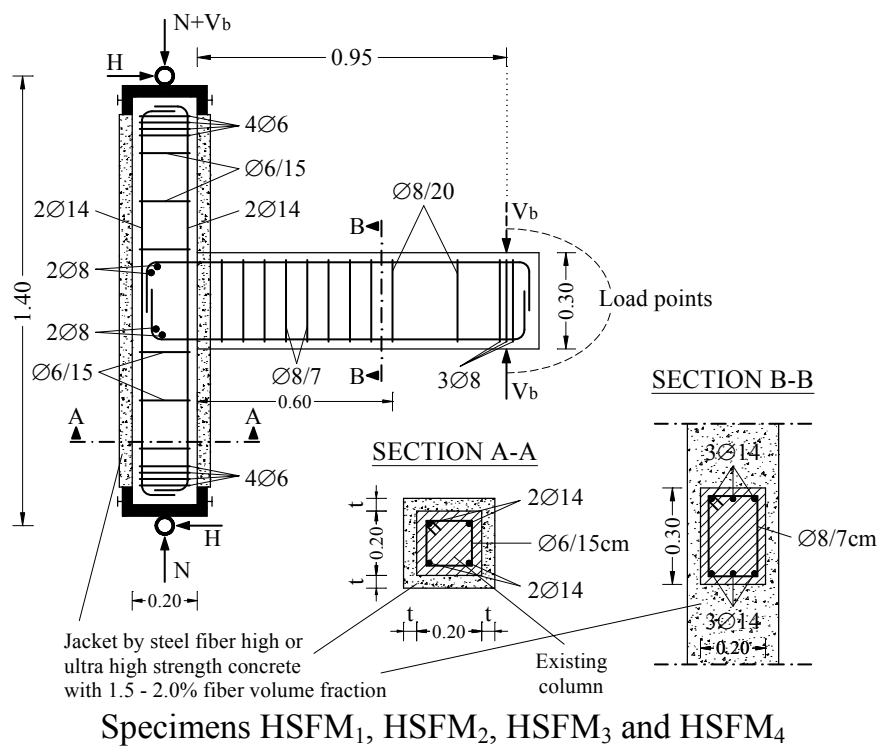

Figure 3: Continued.

3. Subassemblage $M_{1}$ was strengthened by jacketing with ultra high-strength steel fiber-reinforced concrete (UHSFC) with $1.5 \%$ fiber volume fraction in the columns and in the joint region. The thickness of the jacket was only $4.0 \mathrm{~cm}$. The repaired and subsequently retrofitted specimen was named $\mathrm{HSFM}_{1}$ (see figure 3).

4. Subassemblage $\mathrm{M}_{2}$ was retrofitted by jacketing with UHSFC with $1.5 \%$ fiber volume fraction, in the columns and in the joint region. The thickness of the jacket was $6.0 \mathrm{~cm}$. The repaired and strengthened specimen was named $\mathrm{HSFM}_{2}$ (see figure 3).

5. Subassemblage $\mathrm{M}_{3}$ was retrofitted in the same way as specimen $\mathrm{M}_{2}$, but the fiber volume fraction was $1 \%$. Specimen $\mathrm{M}_{3}$ after the interventions was named $\mathrm{HSFM}_{3}$ (see figure 3).

The compressive strengths of the UHSFC used for the strengthening of $\mathrm{HSFM}_{1}, \mathrm{HSFM}_{2}$ and $\mathrm{HSFM}_{3}$ were 106.33MPa, 106.33MPa and $102.30 \mathrm{MPa}$ respectively. The tensile strengths were approximately $12 \mathrm{MPa}$. The steel fibers used were Dramix ZP30/0.6.

6. Subassemblage $\mathrm{M}_{4}$ was retrofitted by jacketing with steel fiber reinforced concrete of high-strength with $1.5 \%$ fiber volume fraction, in the columns and the joint region (see figure 3). The thickness of the jacket was $6.0 \mathrm{~cm}$. The compressive strength of the steel fiber high-strength concrete used was $65 \mathrm{MPa}$. The steel fibers used were also Dramix ZP30/0.6. The subassemblage after the interventions was named $\mathrm{HSFM}_{4}$.

All the above strengthened subassemblages $\mathrm{SO}_{3}, \mathrm{FW}_{2}, \mathrm{HSFM}_{1}, \mathrm{HSFM}_{2}$, $\mathrm{HSFM}_{3}$ and $\mathrm{HSFM}_{4}$ were imposed to the same loading as that of their original subassemblages. All strengthened specimens demonstrated increased strength, stiffness and energy dissipation capacity as compared to those of their original 
specimens (compare hysteresis loops between the original and the upgraded subassemblages in figures 4 and 5 e.g. $\mathrm{O}_{3}-\mathrm{HSFM}_{1}$ ). However, the failure mode of $\mathrm{SO}_{3}$ and $\mathrm{FW}_{2}$ was quite different from that of all upgraded specimens by the new proposed jackets $\mathrm{HSFM}_{\mathrm{i}}$. Thus, although the beams of both $\mathrm{SO}_{3}$ and $\mathrm{FW}_{2}$ yielded, the majority of the damage was concentrated in their joint regions, see failure modes of specimens in figure 5. On the contrary, the failure mode of all specimens HSFM $_{i}$ was the optimum one. Formation of plastic hinge in their beams was observed from the first cycles of loading, while the following cycles resulted in damage concentration only in the critical regions of their beams near their joints. A mixed flexural - shear failure mode was observed in their beams at the end of the tests, which was accompanied by severe buckling of the longitudinal beam reinforcement. The joints and the columns of all these specimens were intact at the conclusion of the tests. This excellent seismic performance of all the $\mathrm{HSFM}_{\mathrm{i}}$ subassemblages was demonstrated both in their failure modes and in their hysteresis loops (figure 5). The seismic behaviour of all these subassemblages was superior to those of specimens $\mathrm{SO}_{3}$ and $\mathrm{FW}_{2}$ retrofitted by reinforced concrete jackets and FRP-jackets.
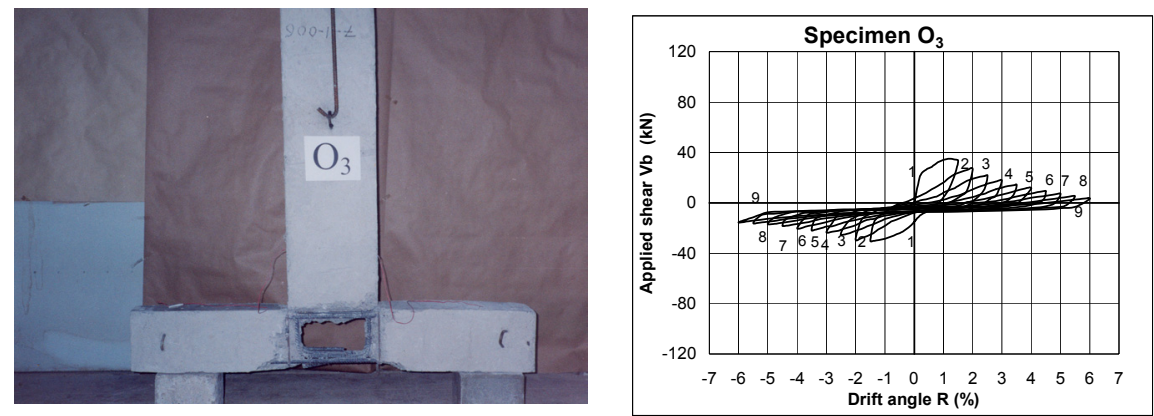

Figure 4: Plots of applied shear versus drift angle and failure mode of the original subassemblage $\mathrm{O}_{3}$.

\section{Conclusions}

1. A new innovative technique for strengthening of poorly detailed structural members of old buildings is proposed for the first time. This method consists of jacketing the structural members with non-shrink, nonsegregating steel fiber concrete of high or ultra high-strength, without the addition of conventional reinforcement in the jackets.

2. This new innovative method was found to be much more effective than the conventional reinforced concrete jackets and especially the FRP-jackets.

3. Beam-column subassemblages, which had failed in pure joint shear failure during seismic-type loading and upgraded in the columns and beam-column joint region by the new innovative technique (patent No 1005657/2007) demonstrated the optimal failure mode, with damage concentration only in the beam region during re-loading with the same loading. 

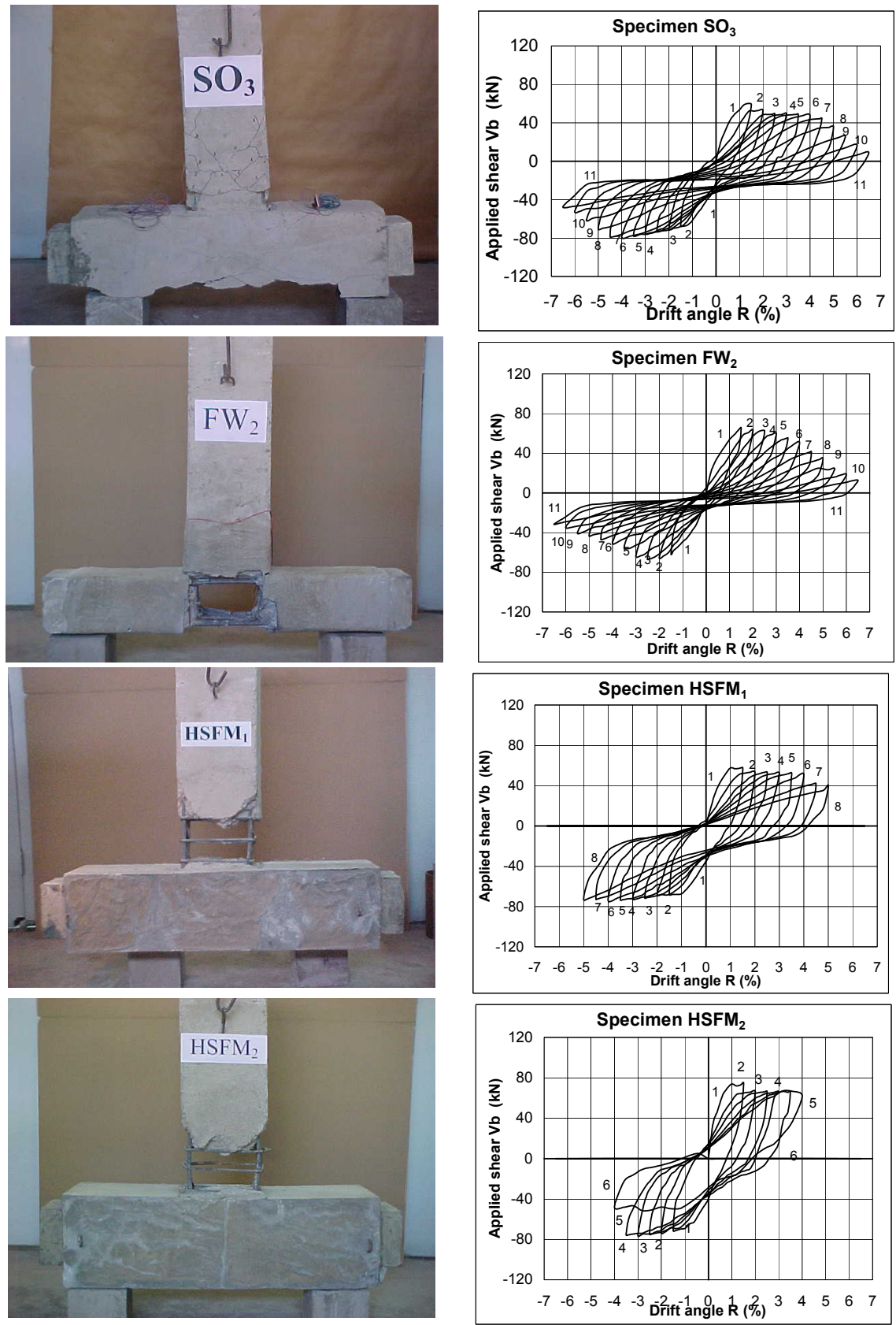

Figure 5: $\quad$ Plots of applied shear versus drift angle and failure mode of the strengthened subassemblages $\mathrm{SO}_{3}, \mathrm{FW}_{2}, \mathrm{HSFM}_{1}, \mathrm{HSFM}_{2}, \mathrm{HSFM}_{3}$ and $\mathrm{HSFM}_{4}$. 

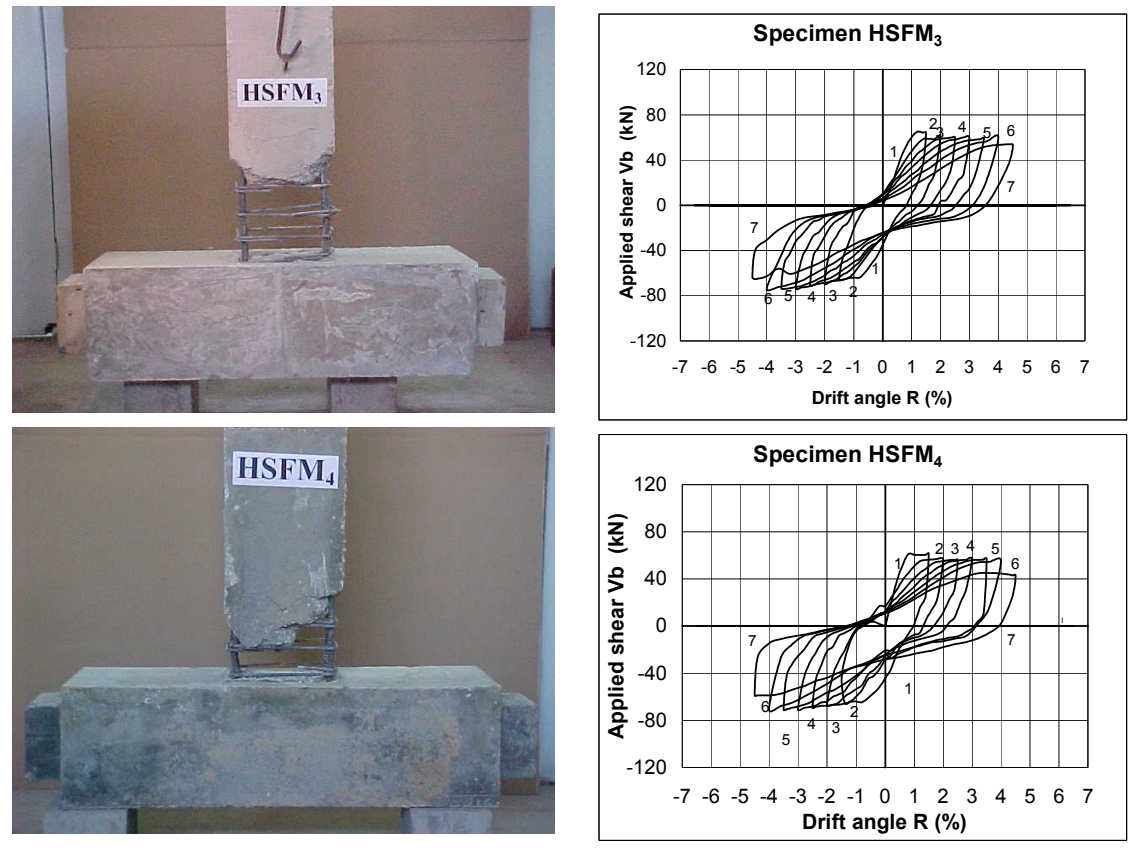

Figure 5: Continued.

Calculations showed that the new innovative method has significantly lower cost than the other well known methods.

\section{Acknowledgements}

The experimental part of this research investigation was sponsored by the Greek General Secretariat of Research and Technology and by the Company ISOMAT S.A. The author gratefully acknowledges the financial support by the sponsors.

\section{References}

[1] Paulay, T. and Park, R., Joints of reinforced concrete frames designed for earthquake resistance. Research Report 84-9, Department of Civil Engineering, University of Canterbury, Christchurch, New Zealand, pp. 72, 1984.

[2] Park, R., A summary of results of simulated seismic load tests on reinforced concrete beam-column joints, beams and columns with substandard reinforcing details. Journal of Earthquake Engineering, 6(2), pp. 147-174, 2002.

[3] Karayannis, C., Chalioris, C. \& Sideris, K., Effectiveness of R/C beamcolumn connection repair using epoxy resin injections. Journal of Earthquake Engineering, 2(2), pp. 217-240, 1998. 
[4] Ilki, A., Darilmaz, K., Bakan, I., Zorbozan, M., Yuksel, E., Saruhan, H. \& Karadogan, F., Jacketing of prefabricated columns. Proc. of the $2^{\text {nd }}$ JapanTurkey Workshop on Earthquake Engineering, Istanbul, pp. 330-335, 1998.

[5] Karayannis, C., Chalioris, C. \& Sirkelis, G., Local retrofit of exterior rc beam-column joints using thin rc jackets - an experimental study. Earthquake Engineering and Structural Dynamics, John Wiley \& Sons, Ltd, 37, pp. 727-740, 2008.

[6] Rodriguez, M. \& Santiago, S., Simulated seismic load tests on two-storey waffle-flat-plate structure rehabilitated by jacketing, ACI Structural Journal, 95(2), pp. 129-145, 1998.

[7] Tsonos, A.G., Seismic repair of exterior R/C beam-to-column joints using two-sided and three-sided jackets. Structural Engineering and Mechanics, An International Journal, 13(1), pp. 17-34, 2002.

[8] UNDP/UNIDO PROJECT RER/79/015, UNIDO, Repair and strengthening of reinforced concrete, stone and brick masonry buildings. In Building Construction under Seismic Conditions in the Balkan Regions, 5, Vienna, 231 pages, 1983.

[9] ACI Committee 440-96, State of the art report on fiber reinforced plastic reinforcement for concrete structures. American Concrete Institute, Detroit, 68 p., 1996.

[10] FIB (CEB-FIP), Retrofitting of concrete structures by externally bonded FRPs with emphasis on seismic applications. Bulletin 35, 218 p., 2006.

[11] Tsonos, A.G., Effectiveness of CFRP-jackets and RC-jackets in postearthquake and pre-earthquake retrofitting of beam-column subassemblages. Engineering Structures, 30(3), pp. 777-793, 2008.

[12] Henager, C.H., Steel Fibrous Ductile Concrete Joints for Seismic-Resistant Structures. Reinforced Concrete Structures in Seismic Zones. ACI Special Publication, SP-53, American Concrete Institute, Detroit, pp. 371-386, 1977.

[13] Hackman, L., Farell, M. \& Dunham, O., Slurry infiltrated mat concrete (SIMCON), Concrete International, 14(12), pp. 53-56, 1992

[14] Dogan, E. \& Krstulovic-Opara, N., Seismic retrofit with Continuous SlurryInfiltrated Mat Concrete Jackets. ACI Structural Journal, 100(6), pp. 713722, 2003.

[15] ACI-ASCE Committee 352-02, Recommendations for design of beamcolumn joints in monolithic reinforced concrete structures (ACI 352R-02). American Concrete Institute, 37pp, 2002.

[16] Tsonos, A.G., Repair of beam-column joints of reinforced concrete structures by the removal and replacement technique. Proc. of the $14^{\text {th }}$ Greek Conf. on Concrete Structures, 15-17 October, Kos Island, B, pp. 583-591, 2003.

[17] Tsonos, A.G., Steel fiber high-strength concrete for the earthquakestrengthening of buildings by jacketing without the use of conventional reinforcement. Proc. of the $15^{\text {th }}$ Greek Conf. on Concrete Structures, 25-27 October, Alexandroupolis, A, pp. 417-427, 2006. 
164 Earthquake Resistant Engineering Structures VII

[18] Tsonos, A.G., Steel fiber high-strength concrete for the strengthening of buildings by jacketing without the use of conventional reinforcement. Scientific Review KTIRIO, 2009 (in press).

[19] Paulay, T. \& Priestley, M.J.N., Seismic design of reinforced concrete and masonry buildings. John Wiley \& Sons, 767pp, 1992.

[20] Tsonos, A.G., Steel fiber reinforced concrete of high-strength for the construction of jackets for earthquake-strengthening of buildings without the use of conventional reinforcement. Patent No 1005657 awarded by the Greek Industrial Property Organization (OBI), 2007. 